Mind the gap: Consequences of inter-role conflicts of freelance journalists with secondary employment in the field of public relations

\author{
Magdalena Obermaier \\ Ludwig-Maximilians-University Munich, Germany
}

\section{Thomas Koch}

Ludwig-Maximilians-University Munich, Germany
2015, Vol. 16(5) 615-629

(C) The Author(s) 2014

Reprints and permissions:

sagepub.co.uk/journalsPermissions.nav DOI: $|0.1| 77 /|4648849| 4528 \mid 42$

jou.sagepub.com

@SAGE

\begin{abstract}
Freelance journalists who are also occupied in public relations have to deal with contrary expectations. Working as a journalist means contributing to the 'public duty' of journalism. When doing public relations work, journalists have to represent the particular interests of their clients. If journalists cannot fulfill these contradictory expectations, they experience inter-role conflicts. What are the consequences of these role conflicts? We conducted a quantitative online survey with German freelance journalists who also do public relations work. We observed that participants are often troubled by interrole conflicts. They feel tense and uncertain whether they see themselves as journalists or as public relations practitioners. Having internalized a normative perception that journalists must not do public relations work, they experience even more intense interrole conflicts and consequently feel more stressed at work. Moreover, even if their job satisfaction on average remains moderate, when facing inter-role conflicts freelance public relations journalists feel less satisfied with their job situation in general.
\end{abstract}

\title{
Keywords
}

Freelance journalists, inter-role conflicts, job satisfaction, public relations, role stress

\section{Corresponding author:}

Magdalena Obermaier, Department of Communication Science and Media Research, Ludwig-MaximiliansUniversity Munich, Oettingenstr. 67, 80538 Munich, Germany.

Email: Magdalena.Obermaier@ifkw.Imu.de 


\section{Introduction}

Nearly half of the freelance journalists in Germany also do public relations (PR) work (cf. DJV, 2009; Meyen and Springer, 2009). However, journalists with this 'double role' are exposed to contrary expectations: on the one hand, as journalists, they have to contribute to the 'public duty', which journalism performs in a democratic society (cf. Riesmeyer, 2007). As PR practitioners, on the other hand, they have to represent their client's particular interests by means of public communication (Barth and Donsbach, 1992: 151). Thus, they effectively work in a gap between journalism and PR. These different normative job approaches put freelance journalists into a difficult situation and can evoke inter-role conflicts. As investigations using role theories demonstrate, these conflicts put a strain on individuals practicing this double role and stimulate stress at work (cf. Love et al., 2010; Miles, 1976). Hence, they are less content with their occupational situation in general (cf. Örtqvist and Wincent, 2006). It is generally acknowledged that a person who feels troubled by conflicts is less efficient at work and more likely to make mistakes. Therefore, freelance journalists who also do PR work may no longer be able to fulfill the demands of their job in an adequate way (cf. Dubinsky and Mattson, 1979; Getzels and Guba, 1954; Walker et al., 1975). Up to now, there has not been any research carried out on the effects of inter-role conflicts on freelance 'PR journalists'. Therefore, this article deals with the following question: What consequences do inter-role conflicts have for freelance journalists who also work in the field of PR?

\section{Theoretical background and research interest}

\section{Inter-role conflicts and consequences of role conflicts}

In order to explain the conflicts that journalists face at work in general as well as the potential conflicts of freelance PR journalists in particular, role theories can be fertile (cf. Fröhlich et al., 2013; Koch et al., 2012). According to role theories, there are certain positions in society, for instance, the position as journalist as well as the position as PR practitioner. Moreover, social positions exist independently of the individuals occupying them. Associated with these social positions are rather consistent clusters of expectations known as roles (cf. Biddle, 1979; Wiswede, 1977: 18). Therefore, one could state that 'a role originates from the expectations about behavior for a position in a social structure' (Örtqvist and Wincent, 2006: 399; also see Rizzo et al., 1970). Consequently, individuals occupying certain positions in society have to live up to these expectations; for instance, they have to carry out their roles as journalists and PR practitioners adequately (cf. Kepplinger, 2011: 41-42). Thus, they have to learn how to fulfill these expectations properly in the different roles they occupy (cf. Biddle, 1979). For example, journalists are socialized in their professional roles during their journalistic training and within their editorial departments. If individuals cannot fully meet role expectations, social sanctions will follow. Hence, persons whose expectations were disappointed will criticize or segregate them for their misbehavior (cf. Dahrendorf, 2006: 40-47; Kepplinger and Maurer, 2008: 165).

However, living up to one's role expectations might not always be easy, since role expectations are likely to contradict each other in some situations. As a consequence, 
role conflicts can emerge. Dahrendorf (2006: 82-84) distinguishes two types of role conflicts: If an individual faces conflicting expectations within a single position, he or she experiences an intra-role conflict (cf. Gross et al., 1958: 448). For instance, journalists working as news writers as well as writers of editorials may be confronted with contradictory expectations concerning their role as journalist. On the one hand, they have to provide information as factual as possible and without advancing their own opinion. On the other hand, when writing editorials, journalists have to carry out a more active role, interpreting the facts given and putting forward their own opinion. Moreover, journalists have to produce their articles and pieces as quickly as possible in order to meet the expectation of actuality in journalism. Yet, they have to carefully investigate the information their work is based on living up to journalistic norms of research (cf. Kepplinger and Maurer, 2008: 166-167). However, role conflicts can also arise if the expectations between two (or more) positions an individual occupies are incompatible. Then, interrole conflicts emerge (cf. Gross et al., 1966: 287-288; Wiswede, 1977: 115). Thus, journalists being a mother or father might be confronted with colliding expectations of journalistic colleagues and their family, as far as long workdays are concerned (cf. Kepplinger and Maurer, 2008: 167-168). Especially, journalists with secondary employment in the field of PR may experience inter-role conflicts. This is due to the fact that a freelance PR journalist is faced with the difficulty that the (normative) expectations on journalists in some situations are completely different from those of PR practitioners. This is the case, for example, when PR journalists have to report critically about the products of their PR clients. Since not (fully) meeting role expectations can lead to social sanctions such as those described above, freelance PR journalists try to prevent such inter-role conflicts. However, it is not always possible to avoid conflicts at work entirely (cf. Koch et al., 2012). Thus, freelance journalists with secondary employment in the field of PR sometimes definitely experience inter-role conflicts.

Apart from social sanctions, being confronted with intra- as well as inter-role conflicts can lead to severe problems for the individuals affected. This phenomenon is known as 'role stress' (cf. Kahn et al., 1964; Wiswede, 1977). Katz and Kahn (1966) differentiate three triggers of role stress: (a) 'role ambiguity', (b) 'role overload', and (c) 'role conflict'. Individuals experience role ambiguity if they do not know how to execute a role in the right way. This is the case if someone is confronted with imprecise or ambivalent role expectations (Rizzo et al., 1970: 151). If time or economic resources are in short supply, individuals feel overburdened and cannot meet the expectations. Thus, they experience role overload (cf. Örtqvist and Wincent, 2006: 400). However, role conflicts are evoked when the expectations in or between roles of someone are incompatible. These three facets of role stress arise independently, meaning that every single component can trigger the experience of role stress. Since freelance PR journalists might especially be confronted with inter-role conflicts, this article focuses on the latter.

Role stress and thus role conflicts in particular can have unpleasant consequences. Therefore, there are many (socio-) psychological, sociological, and economic studies examining the consequences of inter-role conflicts at work. ${ }^{1}$ For instance, several studies prove that role conflicts can lead to both feeling more tension and experiencing more stress at work, and eventually these conflicts can have a negative impact on job satisfaction (cf. McFarland, 2003; Miles, 1976; Örtqvist and Wincent, 2006; Singh, 1998). Yet, 
comparatively few studies from the field of communication science concerned with occupational role conflicts include their (socio-) psychological consequences (cf. Belz et al., 1989; Kepplinger and Maurer, 2008; Ladendorf, 2012). Also, so far there has been no investigation addressing the impact of role conflicts experienced by freelance journalists who also work in the field of PR. All in all, to inquire into the consequences of inter-role conflicts experienced by freelance PR journalists is highly relevant from both a theoretical and social point of view. Thus, the next section is concerned with freelance journalists who also do PR and their potential inter-role conflicts due to this combination.

\section{Inter-role conflicts of freelance journalists with secondary employment in the field of $P R$}

As described above, there are some situations in which journalists with secondary employment in the field of PR face incompatible expectations. This conflict potential can be best deduced from a normative macro-perspective: the German Federal Constitutional Court holds that the press fulfills a public duty. That means it has to publish relevant themes that arise from the public. Therefore, the press has to depict a maximum amount of different arguments and opinions (Riesmeyer, 2007: 30). As a result, citizens can extensively and reliably inform themselves and ultimately form an opinion. PR agents, on the contrary, do not have to fulfill this public duty. They surely 'fulfill an information interest and want to persuade, [but] the former is not obligatory, just as criticizing, controlling and contributing to opinion formation' (Riesmeyer, 2007: 32). With their communications, they primarily serve the interests of particular clients (cf. Barth and Donsbach, 1992: 151). Therefore, the foremost client of PR journalists is the public, since they should contribute to the public duty of journalism (cf. Riesmeyer, 2007: 21). Yet, they also have to communicate the particular interests of their PR clients when doing PR. These contrary expectations can evoke inter-role conflicts. They are likely to arise in certain situations when journalistic expectations collide with the expectations they have to fulfill in the field of PR (e.g. when PR journalists have to report critically about their PR client). Also, the inter-role conflicts PR journalists are confronted with feature a specialty, since often the standard is proposed that journalists must not do PR (cf. Ladendorf, 2012: 91; Schnedler, 2011). Thus, from this point of view, journalists deviate from a journalistic norm by merely taking on the position as PR practitioner and working in the field of PR. Therefore, inter-role conflicts could especially arise when PR journalists have internalized a normative perception that journalists must not have a secondary employment in PR.

Bearing in mind this conflict potential, it is questionable why (freelance) journalists take on secondary employment in the field of PR anyway. In Germany, for example, a job in the field of PR often pays better and offers a more secure job situation than (freelance) journalism (cf. Meyen and Springer, 2009; Weischenberg et al., 2006; also see Weichler, 2005; Wirths, 1994). Nevertheless, freelance PR journalists seem to be less satisfied with their job situation than other freelancers (cf. Buckow, 2011: 90-91, 125). For example, they have to deal with more financial challenges and time pressure than freelancers who do not work in public relations. This can be shown by the fact that they evaluate their future job perspectives as worse and their financial situation as more difficult. So far, there are no scientific findings that these differences in job satisfaction result from conflicts evoked by 
the double role. Yet, there are certain hints that the combination of both roles can easily lead to conflicts. For example, the freelance PR journalists interviewed by Meyen and Springer (2009: 65-70) state that they know about the public critique on combining journalistic and PR work. However, some of them do not consider it to be problematic. According to them, this is because the topics they are working on in PR do not overlap with those in journalism and vice versa (cf. Buckow, 2011: 83, 121; Fröhlich et al., 2013). Nevertheless, as described in the previous passage, freelance PR journalists are likely to experience conflicts when sharing the normative perspective, saying that (freelance) journalists should not do PR work. Correspondingly, we propose in our first hypothesis that

H1. The more freelance PR journalists share the normative perspective that journalists must not work in the field of public relations, the more intense they experience interrole conflicts.

\section{Consequences of inter-role conflicts for freelance journalists with secondary employment in the field of $P R$}

In the next step, we deduce some consequences of inter-role conflicts for (freelance) PR journalists. Many studies demonstrate that individuals experience role conflicts as an additional burden of their job (cf. Bedeian and Armenakis, 1981: 419; Keenan and McBain, 1979: 281; Miles, 1976; Netemeyer et al., 1990: 151; Singh, 1998: 76). Örtqvist and Wincent (2006) state that this feeling of tension is a general 'negative psychological experience based on job-related anxiety' (p. 409). Therefore, if a person experiences role conflicts in his or her job on a regular basis, he or she feels more tension when doing the job. We suppose that this correlation also applies to freelance PR journalists:

$H 2 a$. The more intense freelance PR journalists experience inter-role conflicts, the more they feel tensed at work.

We further suggest that inter-role conflicts have a negative influence on the professional identity of the freelance PR journalists concerned. To establish this connection, we refer to identity theory (cf. Merolla et al., 2012). Its general idea is that in functional differentiated societies, individuals identify with their multiple roles. These diverse role identities are ordered in a hierarchical manner. This order is individually different and can change over time. Thus, if a role is important to persons and they strongly identify with that role, it is more likely that they take on the perspective of that role compared to a role they identify less with (cf. Merolla et al., 2012: 150-153). If PR journalists have been socialized in journalism, for example, during a trainee program, their role as journalist might be more important to them than their role as PR professional. Accordingly, when asked about their job, they would rather talk about their journalistic work than about their PR work. Also, in decision-making processes, they will rather take over the perspective of a journalist than that of a PR practitioner (cf. Merolla et al., 2012: 151). However, experiencing conflicts in their double role, freelance PR journalists are confronted with conflicting expectations that originate from both roles. Thus, in such a role conflict situation, it might be difficult to decide which professional perspective they 
should take in order to ease or resolve the conflict. This insecurity could even be transferred to their professional identity in general: PR journalists experiencing role conflicts might often be insecure whether to consider themselves as journalists or rather as PR practitioners. Therefore, we assume:

$H 2 b$. The more intense freelance PR journalists experience inter-role conflicts, the more they feel insecure about their professional identity.

Also, experiencing role conflicts reinforces the feeling of stress during the work routine (cf. Weeks and Fournier, 2010). McFarland (2003), for example, shows a weak positive correlation between role conflict of his interviewees and their perception of 'manifest stress or simply stress' (p. 311) in the job (McFarland, 2003: 317-319). If freelance PR journalists experience role conflicts and, as a consequence, perceive their double role as aversive (because it makes them feel more tense and insecure), their feeling of stress will be negatively affected:

$H 3 a$. The more freelance PR journalists experience tension due to inter-role conflicts, the more they experience stress at work.

$H 3 b$. The more freelance PR journalists feel insecure about their professional identity due to inter-role conflicts, the more they experience stress at work.

Moreover, several studies show that persons experiencing tension due to role conflicts are less satisfied with their job in general (cf. Abdel-Halim, 1982; Baroudi, 1985; Bartunek and Reynolds, 1983; Bedeian and Armenakis, 1981; Chiu, 1998; Fry and Hellriegel, 1987; Love et al., 2010; Örtqvist and Wincent, 2010; Singh, 1998; Singh and Dubey, 2011). This negative correlation between the perception of tension following role conflicts and job satisfaction is tested anew for freelance PR journalists. Besides, this connection is also plausible for perceived insecurity about professional identity. Thus, if a person is insecure about which professional perspective primarily to take, less job satisfaction could follow. Hence,

H4a. The more freelance PR journalists experience tension due to inter-role conflicts, the lower is their satisfaction with their job situation.

$H 4 b$. The more freelance PR journalists feel insecure about their professional identity due to inter-role conflicts, the lower is their satisfaction with their job situation.

Surely, the consequences of inter-role conflicts do not occur in isolation. They rather reinforce each other. Örtqvist and Wincent (2010), for instance, find that people are less satisfied with their work situation when they experience role stress. This lack of satisfaction results in perceiving role stress more intensely. Therefore, it can be assumed that freelance PR journalists who experience role conflicts react more sensitively to stress at work. This is because they are unhappy with their job in the first place. As a result, they are less satisfied with their job and vice versa (cf. Figure 1):

H5. The more freelance PR journalists experience stress at work due to inter-role conflicts, the lower is their satisfaction with their work situation (and vice versa). 


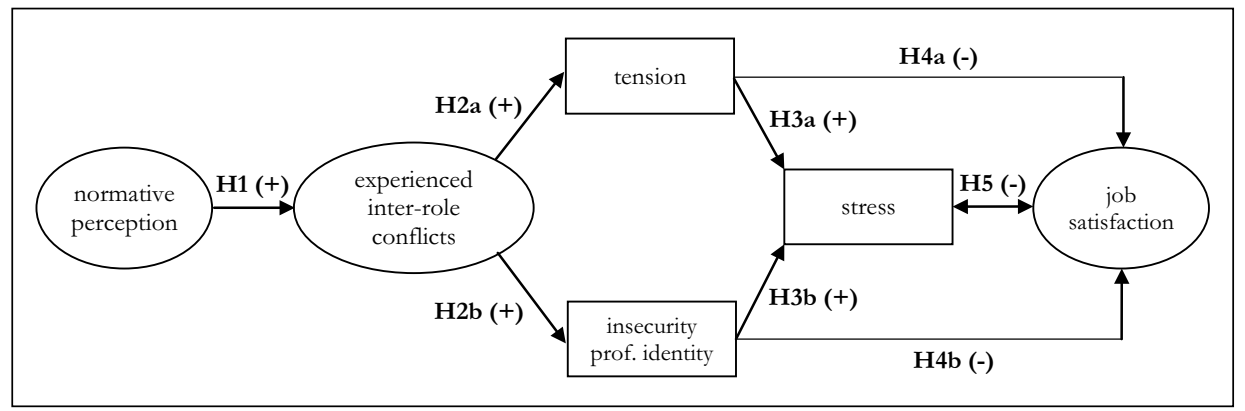

Figure I. Hypothesized model of consequences of inter-role conflicts. (+) indicates a positive correlation and $(-)$ indicates a negative correlation.

\section{Method}

\section{Preliminary considerations and sampling}

In order to get a heterogenic sample of an appropriate size, we conducted an online survey. In April 2012, we wrote emails to 1248 freelance journalists who are registered in an open database of the Deutscher Journalisten-Verband (DJV), an association for German journalists. Of these, 336 persons took part in the survey. That number corresponds to a return rate of 26.9 percent.

In this article, we are interested in freelance journalists who also work in the field of PR. We define these persons by means of three selection criteria. First, every participant has to be a journalist; second, they have to be freelancers; and third, they also have to do PR. According to our first criterion, we define journalists as persons who work full time for a journalistic publication and do journalistic work (cf. Weischenberg et al., 2006: 31). Two filter questions at the beginning of the questionnaire excluded participants who do not work journalistically (but have, for example, either a technical or organizational job at a journalistic medium) or do not work for journalistic media (but, for example, work in the field of corporate publishing). Furthermore, we use the indicator of the 'full-time job' suggested by Weischenberg and colleagues. According to that, our interviewees have to work as journalists at least for half their weekly hours of work (which is a minimum of 20 hours per week) and/or earn half of their income as journalists. Volunteer or part-time journalists are therefore not included in the following analysis. We applied this because we are particularly interested in journalists who also do PR work and, for example, not in PR practitioners writing journalistic articles from time to time. By using our second criterion, we want to make sure that we are interviewing freelance journalists. That means our participants must not have a steady employer and simply follow certain work instructions. In other words, they must not have a contract of employment. Plus, they must not be subject to social insurance contribution because of their work relationship (cf. Götz von Olenhusen, 2008; Meyen and Springer, 2009). Those participants who did not fulfill this second criterion were also excluded from further analysis. According to our third criterion, interviewees also have to do PR work. We asked them directly about any secondary employment in PR, but put the question forward with caution ('According to the Deutscher Journalisten-Verband, $42 \%$ of the freelance journalists also do PR work. Are you working 
in the field of public relations sometimes, too?'). Additionally, we explained that for us 'doing PR work' also means working in corporate publishing. ${ }^{2}$

\section{Participants}

After the selection process described above, 173 participants of the initial 336 interviewees remained in the sample. Of these participants, 55.5 percent were male, and 44.5 percent were female. The average age was 44.82 years (standard deviation $(\mathrm{SD})=8.8$ ) and 80.9 percent of the participants had a university degree. In these general socioeconomic criteria, our sample resembles the structures of the (freelance) journalistic field (cf. Buckow, 2011; DJV, 2009; Meyen and Springer, 2009; Weischenberg et al., 2006). On average, our participants have been working for 12 years $(\mathrm{SD}=8.71)$ as a journalist and have been additionally been working in the field of PR for 9 years $(\mathrm{SD}=7.67)$. Roughly half of our sample (45.9\%) started working as a journalist nearly at the same time as working in the field of PR. The other half (49.4\%) started out working as a journalist and then began to work for PR clients after about 4 years $(\mathrm{SD}=5.50)$. Only 5 percent of the participants worked as PR practitioners in the first place and then began to work as a journalist.

\section{Measures}

House and Rizzo (1972) define inter-role conflicts as 'the degree of incongruity or incompatibility of expectations associated with the role' (p. 474). According to that definition, we built our items measuring inter-role conflict (cf. House and Rizzo, 1972: 477487; also see Rizzo et al., 1970: 155-162). We asked the participants how often they experienced conflicts within their double role. Additionally, we recorded if they have to deal with conflicting demands given these two different professional roles ('Sometimes, I have to do PR work which is in contrast to my journalistic principles' and 'Some of my public relations errands are inconsistent with my journalistic principles'). The three items were measured on a five-stage Likert-scale and describe the latent construct of inter-role conflicts acceptably reliable (Cronbach's $\alpha=.68$ ).

Also, the normative perception that journalists must not have a secondary employment in the field of PR was measured latently. For that purpose, we used the statements, 'A journalist should not also work in the field of PR' and 'I think it can be problematic if journalists also have clients in the field of PR'. These statements were also adequately reliable $(\alpha=.84)$. We were particularly interested in the consequences of inter-role conflicts for PR journalists. To scale this, the questionnaire contained questions asking about the experience of tension ('My double role as journalist and PR-practitioner troubles me') and the perception of stress ('How do you feel in your current job situation?': 'not stressed at all' to 'stressed'). The feeling of insecurity concerning the identity of freelance PR journalists was measured with the statement, 'I am insecure about feeling myself as a journalist or as a PR-practitioner'. Furthermore, we asked the participants about their job satisfaction in general ('How do you feel in your current job situation': 'unhappy' to 'happy', 'not satisfied at all' to 'satisfied'; $\alpha=.90)$. All items were measured on 5-point Likert-scale or by semantic differentials. 


\section{Results}

In order to test our initially proposed model of the consequences of inter-role conflicts for freelance PR journalists, we used structural equation modeling (cf. Babin and Boles, 1998; Boles et al., 1997; Dobreva-Martinova et al., 2002; Jaramillo et al., 2011). Whether the model is consistent with the data was first evaluated with regard to the correlations between the variables used. It can be noticed that all coefficients indicate weak or medium correlations between the model variables in the proposed way. It can be noticed, however, that inter-role conflicts do not affect stress at work and job satisfaction directly (cf. Table 1). Second, we tested the model fit with established model fit indices (cf. Hu and Bentler, 1999; Schermelleh-Engel et al., 2003). The Mplus software was used in order to calculate the fit indices as well as standardized path coefficients (cf. Muthén and Muthén, 1998).

Table I. Correlation matrix.

\begin{tabular}{lllllll}
\hline & 1 & 2 & 3 & 4 & 5 & 6 \\
\hline I. Normative perception & - & & & & & \\
2. Inter-role conflicts & $.21^{* * *}$ & - & & & \\
3. Tension & $.29^{* * * *}$ & $.49 * * *$ & - & & & \\
4. Insecurity professional identity & .11 & $.33^{* * *}$ & $.31^{* * *}$ & - & & \\
5. Stress & $.23^{* * *}$ & .12 & $.25^{* * *}$ & .13 & - & \\
6. Job satisfaction & $-.23^{* * *}$ & -.07 & $-.24 * * *$ & $-.16^{*}$ & $-.30^{* * *}$ & - \\
\hline
\end{tabular}

$*_{p}<.05, * * p<.01, * * * p<.001$.

The 'goodness-of-fit' $\chi^{2}$-test is not significant $\left(\chi^{2}(30)=28.91 ; p=.52\right)$, which means we cannot reject the null hypothesis that the covariance matrix in the populations fits the matrix of our model (cf. Bentler and Bonett, 1980; Bentler and Chou, 1987). Moreover, the comparative fit index (CFI) is higher than .97 and the root mean square error of approximation (RMSEA) is estimated to be lower than .001, which also indicates that the proposed model fits the data (cf. Bentler, 1990; Hu and Bentler, 1999). To sum up, the model fits the data well enough. The standardized path coefficients between the variables also correspond to our assumptions (cf. Figure 2).

According to $\mathrm{H} 1$, a positive correlation between the normative perception and the experience of inter-role conflicts can be seen. Having internalized the norm that a simultaneous occupation in both journalism and PR is illegitimate contributes to the fact that freelance PR journalists experience inter-role conflicts and might even reinforce it. This correlation exists in the model since participants stating that journalists should not do PR work experience inter-role conflicts to a greater extent $(\beta=.36 ; p<.001)$. According to $\mathrm{H} 2 \mathrm{a}$, the experience of inter-role conflicts leads to feeling more tension at work. Furthermore, a potential consequence of inter-role conflicts is that participants are more insecure about their professional identity: in certain situations, it is ambivalent if they should see themselves more like a journalist or a PR practitioner $(\mathrm{H} 2 \mathrm{~b})$. Both assumptions can be maintained on the basis of our data. Thus, freelance journalists who also do PR work feel more tensed at work; they experience more inter-role conflicts resulting 


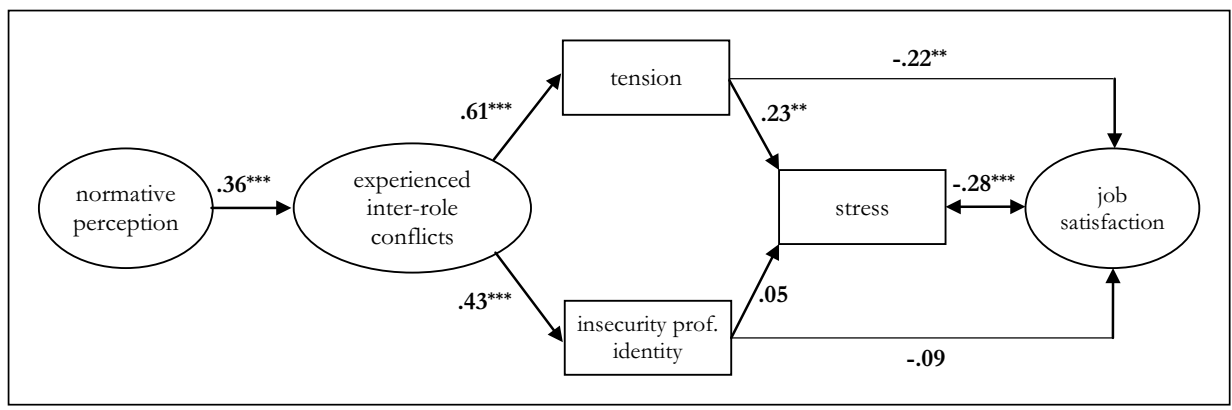

Figure 2. Consequences of experienced inter-role conflicts.

Standard path coefficients $* p<.05, * * p<.01$, *** $p<.001$, model fit $\chi^{2}(30)=28.91, p=.52, \mathrm{CFI}=1.0$, RMSEA $=.001, n=173$.

RMSEA: root mean square error of approximation; CFI: comparative fit index.

from their double role $(\beta=.61 ; p<.001)$. It is also evident that as these journalists seem to feel ambivalent about their professional identity, the intensity of their experience of role conflicts increases $(\beta=.43 ; p<.001)$. These rather strong correlations demonstrate once more that inter-role conflicts can be problematic for the work life of freelance journalists who simultaneously work in the field of PR.

As the correlation matrix indicates (cf. Table 1), the experience of inter-role conflicts is not directly related to stress and job satisfaction of the freelance PR journalists. However, this is not contrary to $\mathrm{H} 3 \mathrm{a}$ and $\mathrm{H} 4 \mathrm{a}$ or $\mathrm{H} 3 \mathrm{~b}$ and $\mathrm{H} 4 \mathrm{~b}$. The first two assume that the tension aroused by inter-role conflicts positively affects stress in the work routine and the job satisfaction of the participants (H3a, H4a). The latter hypotheses proclaim the same correlations for the insecurity about a journalist's own professional identity $(\mathrm{H} 3 \mathrm{~b}$, $\mathrm{H} 4 \mathrm{~b})$. Interestingly, there are no significant correlations between feeling insecure about the professional identity and both stress at work $(\beta=.05 ; p=.50)$ and job satisfaction $(\beta$ $=-.09 ; p=.27$ ) (cf. Figure 2). The experience of tension resulting from inter-role conflicts, however, demonstrates the proposed effects on stress $(\beta=.23 ; p<.01)$ and on job satisfaction of the participants $(\beta=-.22 ; p<.01)$. Consequently, we can maintain H3a and H4a. Moreover, there is a negative indirect effect from role conflicts on job satisfaction which is transmitted over the experience of tension $\left(\beta_{\text {ind }}=-.13 ; p<.01\right)$. Finally, $\mathrm{H} 5$ presumes that stress and job satisfaction reinforce each other in a negative way. More the freelance PR journalists' stress due to inter-role conflicts, lesser the satisfaction with their job situation. In turn, less job satisfaction increases the experience of stress at work and vice versa $(\beta=.28 ; p<.001)$.

\section{General discussion}

This article aimed at elucidating the consequences of inter-role conflicts for freelance journalists who also work in the field of PR. On the one hand, it tries to contribute to filling the research gap concerning potential consequences of inter-role conflicts for freelance PR journalists. We attempt to do that using role theories and thus linking these 
sociological deliberations to journalism research. On the other hand, it is contributing to studies on the effects of role stress (in an occupational context) and seeks to expand them. As a central result, the proposed model fits our data adequately. We can demonstrate that PR journalists who share the normative perception that 'journalists mustn't do PR work' (Schnedler, 2011: 6) experience inter-role conflicts to a greater extent. This is plausible, since if such a norm is 'top of mind', freelancers might be more sensitive to conflicting expectations resulting from the double role and in turn experience these more intensely. We also see that inter-role conflicts are an unpleasant experience for freelancers affected. The freelance PR journalists participating feel troubled by inter-role conflicts and are insecure about which primary professional identity to take on. Thus, for PR journalists, the consequences of inter-role conflicts can be quite negative. Resulting from the experience of inter-role conflicts, participants feel more stressed at work and state a lower job satisfaction. Yet, it has to be pointed out that the average job satisfaction of our participants is rather positive. This may be due to the fact that most (freelance) journalists are intrinsically motivated to do their job (cf. Meyen and Springer, 2009; Weischenberg et al., 2006). Furthermore, for instance, Koch and Obermaier (2013) find that doing PR is a financial must for most of the freelance PR journalists interviewed. Yet, nearly half of them state that it partially is a pleasure and rather interesting to do PR (Koch and Obermaier, 2013: 121-122). Correspondingly, both the rather high intrinsic motivation to do journalistic work and possible gratifications provided by PR work may lead to the rather high average job satisfaction of this study's participants. Alternatively, they might develop 'individual ethics' in order to prevent these conflicts in the first place, for example, by separating the issues they work on in journalism and PR (cf. Koch et al., 2012; Ladendorf, 2012). However, as shown here, inter-role conflicts can also arise when participants have internalized the normative standard that journalists should not do PR. Also, job satisfaction and the experience of stress are clearly negatively related. What the data did not demonstrate are a positive effect of uncertainty about the job identity on the stress experienced at work ( $\mathrm{H} 3 \mathrm{~b})$ and a negative effect on the participant's job satisfaction $(\mathrm{H} 4 \mathrm{~b})$. A possible explanation for this could be that most of the affected freelancers got used to their 'split up' job identity already and are therefore not burdened by it anymore. They are rather well rehearsed to their job situation and feel this insecurity only when reflecting about their job which could have been provoked by the survey.

The explanatory power of the results is certainly limited. Our sample is definitely not representative for all freelance journalists in Germany who also do PR work. However, a representative survey of freelance journalists occupying this double role is hardly practicable. The number of this occupational group is unknown; it is not obligatory for (freelance) journalists to register, not to mention to disclose working in the field of PR as well. Thus, there are always a certain number of unreported cases. At least, the structure of our sample which originates from the publicly available database of the DJV is mainly consistent with the structure of the freelance journalistic field reported by the DJV (2009). Furthermore, the structural equation model has to be scrutinized: We implicitly state that causal correlations exist between our model variables. Since we did not use an experimental design, this causality is merely theoretically assumed. In favor of this assumption, however, from a statistical perspective, the proposed model fits our data well. 
Therefore, our analysis leaves open many possibilities for further research. One could, for example, investigate further factors affecting the experience of inter-role conflicts. Moreover, it might be possible that special groups of freelance PR journalists experience a different amount of inter-role conflicts compared to others. For example, journalists who have already been working for a long time in the field of PR could perceive fewer inter-role conflicts than inexperienced PR journalists. They are already used to doing PR work so they simply ignore inter-role conflicts or manage to prevent them entirely. The same could apply to freelance PR journalists who dedicate a larger percentage of their weekly hours of work for PR or who earn a greater portion of their income doing PR work. Since it seems questionable if an individual working for a PR client more than half of the weekly work hours can be considered as a journalist, our study did not focus on those. Also, it would be interesting to include the journalists' surroundings and thus test the hypothesized model in different contexts. For example, freelance PR journalists who work in an editorial office might be less susceptible to inter-role conflicts. That is because they are surrounded by a peer group who understands their needs to additionally work in the field of PR. Moreover, further research could investigate other factors that positively or negatively influence (freelance) PR journalists' job satisfaction. Thus, following studies could try to provide an answer to the rather paradoxical finding that (freelance) journalists, on the one hand, state having to cope with certain inconveniences doing their job and, on the other hand, feel rather satisfied with their job in general (cf. Meyen and Springer, 2009). In addition, another possible research interest might be to apply role theory to investigate the intra-role conflicts that (freelance) journalists have to face in general. The consequences of inter-role conflicts on the job performance of freelance PR journalists would be also an interesting part to focus on (cf. Ziegler et al., 2012). This is particularly relevant due to the public duty journalism performs.

\section{Funding}

This research received no specific grant from any funding agency in the public, commercial, or not-for-profit sectors.

\section{Notes}

1. In their meta-analysis, Örtqvist and Wincent (2006: 402) identify about 300 studies concerned with effects of role stress in different occupational contexts.

2. We choose this example, since work in corporate publishing often resembles journalistic work from a technical perspective and is thus often not seen as public relations work by (freelance) journalists.

\section{References}

Abdel-Halim AA (1982) Social support and managerial affective responses to job stress. Journal of Occupational Behaviour 3: 281-295.

Babin BJ and Boles JS (1998) Employee behavior in a service environment: A model and test of potential differences between men and women. Journal of Marketing 62: 77-91. 
Baroudi JJ (1985) The impact of role variables on IS personnel work attitudes and intentions. MIS Quarterly 9: 341-356.

Barth H and Donsbach W (1992) Aktivität und Passivität von Journalisten gegenüber Public Relations: Fallstudie am Beispiel von Pressekonferenzen zu Umweltthemen. Publizistik 37: 151-165.

Bartunek JM and Reynolds C (1983) Boundary spanning and public accountant role stress. Journal of Social Psychology 121: 65-72.

Bedeian AG and Armenakis AA (1981) A path-analytical study of the consequences of role conflict and ambiguity. Academy of Management Journal 24(2): 417-424.

Belz A, Talbott AD and Starck K (1989) Using role theory to study cross perceptions of journalists and public relations practitioners. In: Grunig JE and Grunig LA (eds) Public Relations Research Annual, vol. 1. Hillsdale, NJ: Lawrence Erlbaum Associates, Inc., pp. 125-139.

Bentler PM (1990) Comparative fit indexes in structural models. Psychological Bulletin 107(2): 238-246.

Bentler PM and Bonett DG (1980) Significance tests and goodness of fit in the analysis of covariance structures. Psychological Bulletin 88(3): 588-606.

Bentler PM and Chou C-P (1987) Practical issues in structural modeling. Sociological Methods \& Research 16: 78-117.

Biddle BJ (1979) Role Theory: Expectations, Identities, and Behaviors. New York; San Francisco, CA; London: Academic Press.

Boles JS, Johnston MW and Hair JF Jr (1997) Role stress, work-family conflict and emotional exhaustion: Inter-relationships and effects on some work-related consequences. Journal of Personal Selling and Sales Management 17: 17-28.

Buckow I (2011) Freie Journalisten und ihre berufliche Identität: Eine Umfrage unter den Mitgliedern des Journalistenverbands Freischreiber. Wiesbaden: VS Verlag für Sozialwissenschaften.

Chiu RK (1998) Relationships among role conflicts, role satisfactions and life satisfaction: Evidence from Hong Kong. Social Behavior and Personality: An International Journal 26: 409-414.

Dahrendorf R (2006) Homo Sociologicus: Ein Versuch zur Geschichte, Bedeutung und Kritik der Kategorie der sozialen Rolle. Wiesbaden: VS Verlag für Sozialwissenschaften.

DJV (ed.) (2009) Arbeitsbedingungen freier Journalisten. Bericht zu einer Umfrage unter freien Journalisten. Available at: https://www.djv.de/startseite/infos/beruf-betrieb/freie.html (accessed 15 March 2013).

Dobreva-Martinova T, Villeneuve M, Strickland L, et al. (2002) Occupational role stress in the Canadian forces: Its association with individual and organizational well-being. Canadian Journal of Behavioural Science 34: 111-121.

Dubinsky AJ and Mattson BE (1979) Consequences of role conflict and ambiguity experienced by retail salespeople. Journal of Retailing 55: 70-86.

Fröhlich R, Koch T and Obermaier M (2013) What's the harm in moonlighting? A qualitative survey on the role conflicts of freelance journalists with secondary employment in the field of PR. Media Culture \& Society 35(7): 809-829.

Fry LW and Hellriegel D (1987) The role and expectancy participation model: An empirical assessment and extension. Journal of Occupational Behaviour 8: 295-309.

Getzels JW and Guba EG (1954) Role, role conflict, and effectiveness: An empirical study. American Sociological Review 19: 164-174.

Götz von Olenhusen A (2008) Der Journalist im Arbeits- und Medienrecht: Ein Leitfaden. München: Verlag Medien und Recht. 
Gross N, McEachern AW and Mason WS (1958) Role conflict and its resolution. In: Maccoby EE, Newcomb TM and Hartley EL (eds) Readings in Social Psychology. New York: Holt, Rinehart and Winston, pp. 447-459.

Gross N, McEachern AW and Mason WS (1966) Role conflict and its resolution. In: Biddle BJ and Thomas EJ (eds) Role Theory: Concepts and Research. New York: John Wiley \& Sons, pp. 287-296.

House RJ and Rizzo JR (1972) Role conflict and ambiguity as critical variables in a model of organizational behavior. Organizational Behavior and Human Performance 7: 467-505.

Hu LT and Bentler PM (1999) Cutoff criteria for fit indexes in covariance structure analysis: Conventional criteria versus new alternative. Structural Equation Modeling 6: 1-55.

Jaramillo F, Prakash Mulki J and Boles JS (2011) Workplace stressors, job attitude, and job behaviors: Is interpersonal conflict the missing link? Journal of Personal Selling and Sales Management 31(3): 339-356.

Kahn RL, Wolfe D, Quinn A, et al. (1964) Organizational Stress: Studies in Role Conflict and Role Ambiguity. New York: John Wiley \& Sons.

Katz D and Kahn R (1966) The Social Psychology of Organizations. New York: John Wiley \& Sons.

Keenan A and McBain GDM (1979) Effects of type A behaviour, intolerance of ambiguity, and locus of control on the relationship between role stress and work-related outcomes. Journal of Occupational Psychology 52: 277-285.

Kepplinger HM (2011) Journalis mus als Beruf. Wiesbaden: VS Verlag für Sozialwissenschaften.

Kepplinger HM and Maurer M (2008) Das fragmentierte Selbst: Rollenkonflikte im Journalismus - das Beispiel der Berliner Korrespondenten. In: Pörksen B, Loosen W and Scholl A (eds) Paradoxien des Journalismus: Theorie - Empirie - Praxis: Festschrift für Siegfried Weischenberg. Wiesbaden: VS Verlag für Sozialwissenschaften, pp. 165-182.

Koch T and Obermaier M (2013) Schwieriger Spagat. Eine quantitative Befragung freier Journalisten mit Nebentätigkeiten im PR-Bereich. $S C \mid M$ - Studies in Communication $\mid$ Media 2(1): 115-127.

Koch T, Fröhlich R and Obermaier M (2012) Tanz auf zwei Hochzeiten. Rollenkonflikte freier Journalisten mit Nebentätigkeiten im PR-Bereich. Medien- \& Kommunikationswissenschaft 60(4): 520-535.

Ladendorf M (2012) Freelance journalists' ethical boundary settings in information work. Nordicom Review 33(1): 83-98.

Love KM, Tatman AW and Chapman BP (2010) Role stress, interrole conflict, and job satisfaction among university employees: The creation and test of model. Journal of Employment Counseling 47: 30-37.

McFarland RG (2003) Crisis of conscience: The use of coercive sales tactics and resultant felt stress in the sales person. Journal of Personal Selling and Sales Management 23: 311-325.

Merolla DM, Serpe RT, Stryker S, et al. (2012) Structural precursors to identity processes: The role of proximate social structures. Social Psychology Quarterly 75(2): 149-172.

Meyen M and Springer N (2009) Freie Journalisten in Deutschland: Ein Report. Konstanz: UVK Verlagsgesellschaft.

Miles RH (1976) A comparison of the relative impacts of role perceptions of ambiguity and conflict by role. Academy of Management Journal 19(1): 25-35.

Muthén LK and Muthén BO (1998) Mplus: The Comprehensive Modeling Program for Applied Researchers. Los Angeles, CA: Muthén \& Muthén.

Netemeyer RG, Johnston MW and Burton S (1990) Analysis of role conflict and role ambiguity in a structural equations framework. Journal of Applied Psychology 75: 148-157. 
Örtqvist D and Wincent J (2006) Prominent consequences of role stress: A meta-analytic re-view. International Journal of Stress Management 13(4): 399-422.

Örtqvist D and Wincent J (2010) Role stress, exhaustion, and satisfaction: A cross-lagged structural equation modeling approach supporting Hobfoll's loss spirals. Journal of Applied Social Psychology 40(6): 1357-1384.

Riesmeyer C (2007) Wie unabhängig ist Journalismus? Zur Konkretisierung der Determinationsthese. Konstanz: UVK Verlagsgesellschaft.

Rizzo JR, House RJ and Lirtzman SI (1970) Role conflict and ambiguity in complex organizations. Administrative Science Quarterly 152(2): 150-163.

Schermelleh-Engel K, Moosbrugger H and Müller H (2003) Evaluating the fit of structural equation models: Tests of significance and descriptive goodness-of-fit measures. Methods of Psychological Research Online 8(2): 23-74.

Schnedler T (2011) Profession: Grenzgänger. Journalisten zwischen Journalismus und PR. In: Getrennte Welten? Journalismus und PR in Deutschland. netzwerk recherche e.V. Available at: http://www.netzwerkrecherche.de/files/nr-werkstatt-20-getrennte-welten-2011.pdf (accessed 20 March 2014).

Singh AP and Dubey AK (2011) Role of stress and locus of control in job satisfaction among middle managers. Journal of Organizational Behavior 10(1): 42-56.

Singh J (1998) Striking a balance in boundary-spanning positions: An investigation of some unconventional influences of role stressors and job characteristics on job outcomes of salespeople. Journal of Marketing 62: 69-86.

Walker OC Jr, Churchill GA Jr and Ford NM (1975) Organizational determinants of the industrial salesman's role conflict and ambiguity. Journal of Marketing 39: 32-39.

Weeks WA and Fournier C (2010) The impact of time congruity on salesperson's role stress: A person-job fit approach. Journal of Personal Selling and Sales Management 30(1): $73-90$.

Weichler K (2005) Freier Journalismus. In: Weischenberg S, Kleinsteuber HJ and Pörksen B (eds) Handbuch Journalismus und Medien. Konstanz: UVK Verlagsgesellschaft, pp. 69-73.

Weischenberg S, Malik M and Scholl A (2006) Die Souffleure der Mediengesellschaft: Report über die Journalisten in Deutschland. Konstanz: UVK Verlagsgesellschaft.

Wirths S (1994) Freiberuflerinnen im Journalismus: Selbstverständnisse, Arbeitsformen, Probleme und Strategien. Münster: Lit.

Wiswede G (1977) Rollentheorie. Stuttgart; Berlin; Köln; Mainz: W. Kohlhammer.

Ziegler R, Hagen B and Diehl M (2012) Relationship between job satisfaction and job performance: Job ambivalence as a moderator. Journal of Applied Social Psychology 42(8): 2019-2040.

\section{Author biographies}

Magdalena Obermaier, M.A., is a research assistant at the Department of Communication Science and Media Research, Ludwig-Maximilians-University Munich, Germany. Her research focuses on media effects, effects of persuasive communication, and the relationship between journalism and public relations.

Thomas Koch, $\mathrm{PhD}$, M.A., is a postdoctoral research fellow at the Department of Communication Science and Media Research, Ludwig-Maximilians-University Munich, Germany. His research focuses on effects of persuasive communication, the relationship between journalism and public relations, media use, and political communication. 